\title{
Gastric Volvulus with Mixed Hiatal Hernia: A Rare Picture of Acute Abdomen
}

\author{
Mide Volvulusu ile Birlikte Mikst Hiatal Herni: Nadir Görülen Bir Akut Karın Tablosu
}

\author{
Hüseyin Pülat', Oktay Karaköse', Mehmet Fatih Benzin², Şeyma Benzin³, Tevfik Bülbül², Mahmut Bülbül² \\ 'Department of Surgical Oncology, Faculty of Medicine, Süleyman Demirel University, Isparta, Turkey \\ 2Department of General Surgery, Faculty of Medicine, Süleyman Demirel University, Isparta, Turkey \\ ${ }^{3}$ Department of Radiology, Faculty of Medicine, Süleyman Demirel University, Isparta, Turkey
}

\section{ABSTRACT}

Introduction: Gastric volvulus occurs when the stomach rotates more than 180 degrees, and it is a rare surgical condition. It is a potentially life-threatening entity, and most cases of gastric volvulus occur in association with a hiatal hernia. Gastric volvulus is a rare condition and presents with nonspecific abdominal symptoms. Hence, endoscopy and computed tomography can help the diagnosis. Emergent surgical approach is mandatory.

Case Report: We present in this article a 73-year-old woman who had acute abdominal symptoms. Endoscopic and radiological imaging revealed gastric volvulus with a mixed hiatal hernia and choledocholithiasis. The patient underwent emergent surgery, and she was discharged healthy.

Conclusion: Borchardt's triad during a hiatal hernia makes the physician consider acute gastric volvulus. The diagnosis should be corrected with endoscopic and radiological imaging. Proper surgical treatment methods should be applied. Other abdominal pathologies, such as choledocholithiasis, may accompany this condition, and they should also be kept in mind.

Keywords: Gastric volvulus, hiatal hernia, choledocholithiasis Received:22.07.2013 Accepted: 23.09.2013

\section{ÖZET}

Giriș: Mide volvulusu, nadir rastlanılan cerrahi bir durumdur ve midenin 180 derecenin üzerindeki rotasyonları ile meydana gelir. Bu, potansiyel olarak hayatı tehdit eden bir durumdur ve çoğu olguda hiatal herniyle ilişkilidir. Nadir görülen mide volvulusu, özgül olmayan karın semptomları ile kendini gösterdiğinden endoskopi ve bilgisayarlı tomografi ile tanı konulabilir. Mutlak acil cerrahi girişim, gereklidir.

Olgu Sunumu: Bu yazıda akut karın şikâyetleri olan, endoskopik ve radyolojik tetkikler sonucu mide volvulusu ile birlikte mikst hiatal herni ve primer koledok taşı tanısı konulan, acil cerrahi girişim ile tedavi edilen 73 yaşında kadın hasta sunulmaktadır.

Sonuç: Hiatal hernili olgularda Borchardt triadı görülmesi durumunda akut mide volvulusu düşünülmeli, endoskopik ve radyolojik tanı doğrulanıp hastaya uygun cerrahi tedavi yöntemi uygulanmalıdır. Ayrıca beraberinde koledokolityazis gibi başka karın patolojilerinin de bulunabileceği akılda tutulmalıdır.

Anahtar Kelimeler: Mide volvulusu, hiatal herni, koledokolityazis Geliş Tarihi: 22.07.2013 Kabul Tarihi: 23.09.2013

\section{Giriş}

Akut mide volvulusu, mide veya ona ait olan bir parçanın 180 derecenin üzerindeki rotasyonu ile meydana gelir. Mide volvulusu nadir görülür ve bu nedenle insidansı, tam olarak bilinmemektedir (1). Olguların \%75'inde mide volvulusu, başka bir patolojiye sekonder olarak görülür. Bu sekonder patolojiler; hiatus hernileri, sol diafragma evantrasyonu, pilor stenozu veya karın içi yapışıklıklar olabilir (2). Tanısal değeri yüksek tek bir laboratuvar veya radyolojik tetkik olmadığı için mide volvulusu tanısı koymak güçtür. Bilgisayarlı tomografi, acil cerrahi girişim düşünülen olgularda tercih edilebilir (1). Geleneksel cerrahi tedavisi, laparotomi ile midenin detorsiyonunu, fiksasyonunu ve diafragmatik fıtık onarımını içerir (3). Bu sunumda mikst tip hiatal herniye bağlı gelişen ve primer koledokolityazis ile birlikte olan akut mide volvulus olgusu tartışılacaktır. 


\section{Olgu Sunumu}

Anamnezinde uzun süredir epigastrik bölgede rahatsızlık hissi, geğirme, bulantı ve erken tokluk hissi şikayetleri olan 73 yaşında kadın hastanın son 3 gündür her yemekten sonra şiddetlenen epigastrik bölgede ağrı, bulantı ve öğürme şikayetleri nedeniyle acil servise başvurdu. Hastanın özgeçmişinden hipertansiyonu olduğu, 10 yıl önce kolelityazis nedeniyle hastaya kolesistektomi uygulandığı öğrenildi. Hastanın geliş vital bulguları; kan basıncı: 140/90 mmHg, ateşi: 37,50 C, nabız: 100 atım/dk. idi. Hastanın yapılan fizik muayenesinde epigastrik bölgede hassasiyeti mevcut idi. Laboratuvar tetkiklerinde lökosit sayımı \%94,2 (Normal değer:

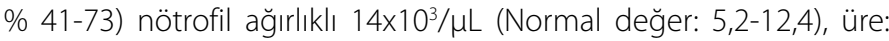
48 mg/dL (Normal değer: 10-40), amilaz: 328 U/L (Normal değer: 28-100), Laktat Dehidrogenaz: $307 \mathrm{U} / \mathrm{L}$ (Normal değer: 0-247) değerleriyle yüksekti. Potasyum: 2,6 mmol/L (Normal değer: 3,35,1), albumin: 3 g/dL (Normal değer: 3,5-5,2) değerleriyle düşüktü. Alanin transaminaz, aspartat transaminaz, total bilirübin ve direkt bilirübin, alkalen fosfataz, gama glutamil transferaz değerleri normal aralıkta idi. Yapılan batın ultrasonografisinde koledok 12 mm ile dilate, intrahepatik safra yolları (IHSY) dilate saptandı. Bunun üzerine çekilen manyetik rezonans kolanjiopankreatografisinde koledok çapı 16 mm olarak ölçüldü. Koledok distalinde lümen içinde 1 cm'lik kalkül saptandı. IHSY, dilate idi. Çekilen direkt göğüs radyografisinde mediasteni genişlemiş olduğu görüldü. Hastaya nazogastrik sonda takılmaya çalışıldı. Sonda ilerletilemedi. Yapılan özofagogastroduodenoskopisinde korpus, orta kesimde çepeçevre daralmış (kum saati gibi) olduğu görüldü. Çekilen bilgisayarlı toraks tomografisinde özofagogastrik bileşkenin subdiafragmatik yerleşimli olduğu görüldü ve mikst tipte hiatal herni saptandı (Resim 1). Çekilen tüm karın bilgisayarlı tomografisinde mide korpus ve antrumu toraks boşluğu içine yer değiştirmiş olup görünüm organoaksiyel volvulus ile uyumlu olduğu (Resim 2), midedeki herniasyon nedeniyle kalbin anteriora itildiği, mezenterik yağ doku dansitesinin artmış olduğu görüldü. Bu bulgular doğrultusunda hastaya mide volvulu ile birlikte mikst tipte hiatal herni ve primer koledok taşı tanısı konuldu. Hasta preoperatif hazırlık ve hidrasyonu takiben acil ameliyata alındı. Orta hat kesiyle yapılan gözlemde kardiyanın özofagus

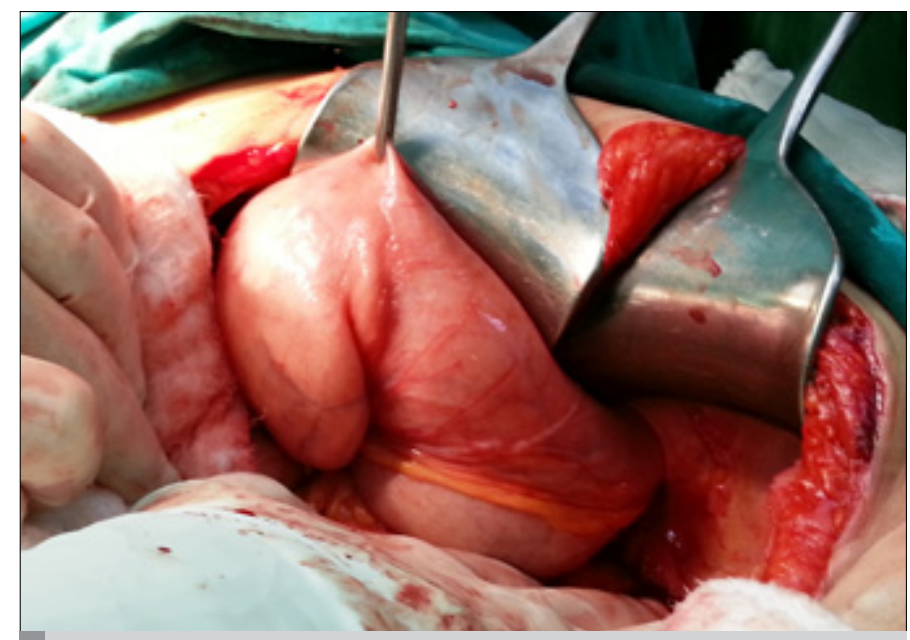

Resim 1. Midenin volvulusunu, toraks ve batın boşluğundaki yerleşimini gösteren kronal tomografi görüntüsü. içine doğru ilerlediği, özofagus sağ lateralinde yaklaşık 4x5 cm'lik bir diafragmatik defekt olduğu ve bu defektten midenin antrum ve korpusu mediastene doğru ilerlediği görüldü. Mide, karına redükte edildiğinde büyük kurvatur, midenin uzun aksı üzerinde küçük kurvatur üzerine döndüğü (organoaksiyel volvulus) görüldü. Volvulus, detorsiyone edildi. Mide kanlanması ve peristaltizminin normal olduğu görüldü. Gastropeksi ve paraözofageal herni onarımı yapıldı. Koledokolityazis için koledokotomi yapıldı. Taş çıkarıldı. Koledokoduodenostomi uygulandıktan sonra ameliyata son verildi. Hastaya nazogastrik sonda takılıp 3 gün parenteral sıvı ve antibiyotik tedavisi verildi. Postoperatif 3. gün oral sıvı gıda, daha sonra normal gıda verilen hastada herhangi bir komplikasyon gelişmedi. Hasta postoperatif 7. günde taburcu edildi. Postoperatif 3. ayda yapılan kontrolünde herhangi bir problem saptanmadı.

\section{Tartışma}

Akut mide volvulusu, mide veya ona ait olan bir parçanın 180 derecenin üzerindeki rotasyonu ile meydana gelir. Mide volvulusu, en sık 50'li yaşlarda ve tüm ırklar ve cinsiyetler arasında eşit sıklıkta
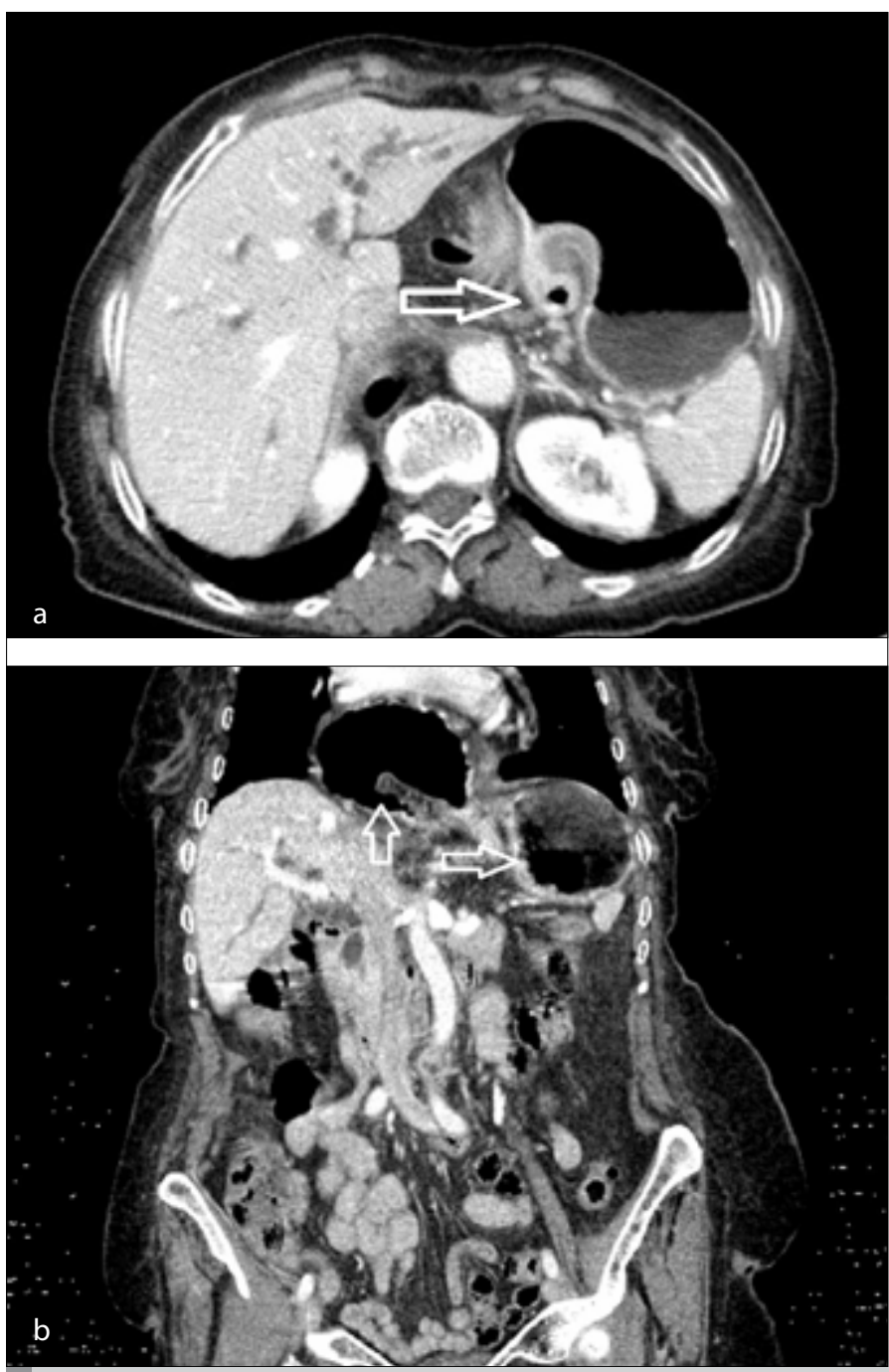

Resim 2. Midenin girdap şeklindeki dönerek oluşturduğu volvulusu gösteren tomografi görüntüsü 
görülür (1). Olguda sunduğumuz hasta, 73 yaşında ve bayandı. Mide volvulusu, etyolojisine göre primer (idiyopatik) veya sekonder olabilir. Karın içerisinde başka bir patolojinin eşlik etmediği mide volvulusu olguları, "primer" olarak tanımlanır ve mide bağlarının çok uzamasıyla oluşurlar. Olguların \% 75'inde ise mide volvulusu, başka bir patolojiye sekonder olarak meydana gelir. Bu sekonder patolojiler; hiatus hernileri, sol diafragma evantrasyonu, pilor stenozu veya karın içi yapışıklıklarıdır (2). Bizim olgumuzda mikst tip hiatal herniye bağlı akut mide volvulusu mevcuttu.

Anatomik olarak ise mide volvulusunun 4 tipi vardır (4).

Tip 1 (organoaksiyel volvulus): Midenin pilor - kardia ekseninde rotasyona uğraması sonucu oluşur. \%59 oranı ile en sık görülen mide volvulusu tipidir. Orta ve ileri yaşta sıklıkla görülür ve diafragmatik defekt ile birliktedir.

Tip 2 (mezenteroaksiyel volvulus): Midenin transvers planda küçükbüyük kurvatura ekseninde rotasyona uğraması sonucu oluşup \%29 oranında ve çocukluk yaşta görülür.

Tip 3 (kombine volvulus): \%2 oranı ile en az görülen tiptir (5).

Tip 4 (sınıflandırılamayan volvulus): Olguların yaklaşık \%10'unda görülür.

Bizim olgumuz, organoaksiyel tipteydi.

Mide volvulusları nadiren de olsa akut olarak strangülasyon veya obstrüksiyon şeklinde kendini gösterebilir ve sıklıkla akut karına yol açarlar. Fakat midenin zengin damarlanma sistemi nedeniyle midede nekroz gelişimi nadirdir. Akut olgularda volvulus sıklıkla organoaksiyel tiptedir. Kronik veya tekrarlayan mide volvulusları, daha çok görülür. Semptomsuz kronik volvulus olguları, direkt toraks grafisi veya baryumlu inceleme esnasında tesadüfen saptanabilirler. Semptomlu olgularda ise şikayetler, sıklıkla hafiftir ve üst karın bölgesinde sürekli veya aralıklı bir rahatsızlık şeklinde kendini gösterebilir. Hasta yemek sırasında şişkinlik ve rahatsızlık duygusundan, daha sonra ise geğirme ve kusmadan yakınabilir. Eşlik eden diafragma evantrasyonu veya büyük bir paraözofageal herni varsa hasta nefes darlığından yakınabilir (2)

Mide volvulusu, hayatı tehdit eden bir klinik tablo olup tanıda şüphe çok önemlidir. Mide volvulusu tanısında Borchardtın triadı olarak adlandırılan şiddetli epigastrik ağrı ve distansiyon, inatçı öğürmeye rağmen kusamama ve nazogastrik tüp yerleştirmede başarısızlık klinik bulgularının birarada olması kullanılabilir (6). Ancak olguların \% 75'inde Borchardt'ın klasik triadı birarada bulunurken \% 25'inde ise bu bulgular saptanmayabilir. Bizim olgumuzda epigastrik bölgede distansiyon dışındaki diğer bulgular mevcut idi. Epigastrik bölgede distansiyonun olmamasını, midenin toraks boşluğuna geçmesine bağlı olduğunu düşünmekteyiz.

Tanısal değeri yüksek tek bir laboratuvar veya radyolojik tetkik olmadığı için mide volvulusu tanısını koymak güçtür. Mide volvulusunun tanısında bilgisayarlı tomografinin etkin bir tetkik olduğu ifade edilmektedir. Bilgisayarlı tomografi, öncelikle acil cerrahi girişim düşünülen olgularda bilgi edinmek için çekilebilir (1). Bizim olgumuzda tanı, endoskopi ve bilgisayarlı tomografi ile konuldu.

Yaptığımız literatür taramasında mide volvulusu ile birlikte mikst tipte hiatal herni ve primer koledok taşı birlikteliği saptayamadık.

Mide volvulusunun tedavisi, cerrahidir $(7,8)$. Cerrahi tedavi, açık veya laparoskopik şekilde uygulanabilir (3). Bizim olgumuzda mikst tip hiatal herni ve koledokolityazis olması nedeni ile açık cerrahi tedavi, tercih edildi. Cerrahi tedavide esas olan volvulus redüksiyonu, gastropeksi ve bizim olgumuzda olduğu gibi varsa diafragmatik defektlerin onarımıdır $(3,9)$.

Mide volvulusu durumunda tedavideki gecikme; strangülasyon, perforasyon, pankreatit, peritonit, şok gibi çok ağır komplikasyonlara ve hatta ölüme yol açabilir. Akut mide volvulus olgularında mide iskemisi, perforasyonu veya nekrozuna bağlı olarak \%42-56 oranında mortalite gelişebilir (1).

\section{Sonuç}

Bizim bu olguda sunduğumuz gibi hiatal hernili hastalarda karın ağrısı, öğürme, nazogastrik sonda takılamama (Borchardt triadı) gibi durumlarda akut mide volvulusu düşünülmeli, endoskopi yapılmalı ve bilgisayarlı tomografi çekilerek tanı doğrulanıp hastaya uygun cerrahi yöntem uygulanmalıdır. Ayrıca beraberinde koledokolityazis gibi başka karın patolojilerinin de bulunabileceği akılda tutulmalıdır.

Hasta Onamı: Yazılı hasta onamı bu olguya katılan hastadan alınmıştır.

Hakem değerlendirmesi: Dış bağımsız.

Yazar Katkıları: Fikir - H.P., O.K.; Tasarım - M.F.B., Ş.B.; Denetleme - T.B., M.B.; Literatür taraması - H.P.; Yazıyı yazan - H.P.; Eleştirel inceleme O.K., M.F.B.

Çıkar Çatışması: Yazarlar çıkar çatışması bildirmemişlerdir.

Finansal Destek: Yazarlar bu çalışma için finansal destek almadıklarını beyan etmişlerdir

Informed consent: Written informed consent was obtained from the patient who participated in this case.

Peer review: Externally peer-reviewed.

Author Contributions: Concept - H.P., O.K.; Design - M.F.B., Ş.B.; Supervision - T.B., M.B.; Literature review - H.P.; Writer -H.P.; Critical review - O.K., M.F.B.

Conflict of interest: The authors declared no conflict of interest. 
Financial Disclosure: The authors declared that this study has received no financial support.

\section{Kaynaklar}

1. Chau B, Dufel S. Gastric volvulus. Emerg Med J 2007; 24: 446-7. [CrossRef]

2. Ellis H. (çev: Andican A.): Divertikül, volvulus ve ileus. In Schwartz SI, Ellis H., ed(s) (çev. editörü: Andican A.). Maingot Abdominal Operasyonlar. 8. baskı. İstanbul: Nobel Tıp Kitabevi; 1989. s. 531-48.

3. Chiue CC, Wang W, Wei PL, Lee WJ. Giant diaphragmatic hernia intrathoracic gastric volvulus. Endoscopy 2006; 38: 52-3. [CrossRef]

4. Lee $T C$, Liu KL, Lin MT, Wang HP. Unusual cause of emesis in an octogenarian: organoaxial gastric volvulus associated with paraesophageal diaphragmatic hernia. J Am Geriatr Soc 2006; 54: 555-7. [CrossRef]
5. Wasselle JA, Norman J. Acute gastric volvulus: Pathogenesis, diagnosis, and treatment. Am J Gastroenterol 1993; 88: 1780-4.

6. Germanos S, Gourgiotis S, Saedon M, Lapatsanis D, Salemis NS. Severe abdominal pain as a result of acute gastric volvulus. Int J Emerg Med 2010; 3: 61-2. [CrossRef]

7. Bawahab M, Mitchell P, Church N, Debru E. Management of acute paraesophageal hernia. Surg Endosc 2009; 23: 255-9. [CrossRef]

8. Schiano di Visconte M, Barbaresco S, Burelli P, Da Ros D, Di Bella R, Lombardo C, et al. Acute abdomen due to a strangulated and perforated para-esophageal hernia. A case report. Chir Ital 2002; 54:563-7.

9. Koontz CS, Wulkan M. Lesions of the stomach. In Holcomb GW, Murphy JP (eds). Ashcraft's Pediatric Surgery. 5th ed. Philadelphia: Saunders Elsevier; 2010. p. 391-9. [CrossRef] 